\title{
Habitat selection and the evolutionary aesthetics of landscape preference
}

\author{
Marko Škorić, Aleksej Kišjuhas \\ Faculty of Philosophy, University of Novi Sad, Novi Sad, RS \\ mskoric@ff.uns.ac.rs \\ aleksej.kisjuhas@ff.uns.ac.rs
}

\begin{abstract}
This paper analyses the processes of habitat selection and human landscape preferences from an evolutionary perspective, with the aim of demonstrating how humans aesthetically choose, assess and aspire to live in an environment in which our species and our ancestors evolved in during the pre-Neolithic period. We present the basics of evolutionary aesthetics, then analyse the process of habitat selection and the most influential evolutionary theories of landscape preference. Finally, we refer to applied empirical research and point out that a comprehensive evolutionary theory must also take into account the psychological and cultural elements that affect human well-being.
\end{abstract}

KEY WORDS - evolutionary aesthetics; habitat selection; biophilia; landscape preference

\section{Izbira življenjskega prostora in evolucijska estetika krajinskih preferenc}

\begin{abstract}
IZVLEČEK - V članku analiziramo proces izbire življenjskega prostora in preference ljudi pri izbiri krajine iz evolucijske perspektive z namenom, da pokažemo, kako ljudje na podlagi estetike izbirajo, ocenjujejo in stremijo $k$ življenju $v$ okolju, $v$ katerem so se v obdobju pred neolitikom razvijali naša vrsta in naši predniki. Predstavljamo osnove evolucijske estetike, nato analiziramo proces izbire življenjskega prostora in najbolj vplivne evolucijske teorije o krajinskih preferencah. Na koncu se sklicujemo na uporabne empirične raziskave in pokažemo, da mora celovita evolucijska teorija upoštevati tudi psihološke in kulturne elemente, ki vplivajo na dobro počutje ljudi.
\end{abstract}

KLJUČNE BESEDE - evolucijska estetika; izbira življenjskega prostora; krajinske preference

\section{The biology of aesthetics}

As a field of research, aesthetics generally does not relate to biology or evolution, but primarily to culture and learning, although there is no doubt that evolutionary theory can reveal a lot about aesthetic preferences. Roughly speaking, aesthetics studies what we like or dislike, and the important question is whether standards of judgments can be learned or are (to a greater or lesser extent) inherited. In line with the tendency of social scientists throughout most of the 20th century to ignore knowledge that came from biology (Degler 1991), theorists of aesthetics and the arts mostly did not advocate ideas about the existence of human nature, but emphasized his- toricist explanations based on historical contexts and cultural factors. Thus, aesthetic values are usually seen as referring to the prevalent social values in a particular culture, and that kind of social or cultural constructivism also implies relativism regarding aesthetic values.

The situation changed with the rise of evolutionary psychology, which began to advocate aesthetic universalism (e.g., Dutton 2003; Thornhill 1998; 2003; Dissanayake 1992), and the answer to the question of why the position of universalism is compatible with evolutionary psychology is simple. All organi- 
sms are the products of evolution, which is not brought into question by scientists, while there is some controversy concerning the impact of evolution on behaviour (e.g., Segerstråle 2000). Evolutionary psychologists acknowledge the influence of evolution through natural selection both on the behaviour and mind of humans, and according to these ideas human nature was formed long before the Holocene, and endows us with certain capacities which are not consequences of socialization, learning, traditions and the like (e.g., Tooby, Cosmides 1992).

We argue that there is sufficient convincing evidence to conclude that human nature exists in the form of genetic biases that affect our perception, decisionmaking and behaviour in general (e.g., Wilson 1978). Cultural evolution is influenced by biology, although the biological evolution of the brain has taken place in a social context, so it is not disputed that culture plays a large role in human behaviour. Human culture is part of human biology, thus any attempt to separate them is artificial and misguided (e.g., Boyd, Richerson 2005). Only from an evolutionary perspective can we understand why our knowledge fits our environment; that is, how we manage to understand the world around us. Likewise, an evolutionary perspective offers an explanation as to why we know so much about the world, although we have very limited personal experience. And finally, only through evolution can we explain why our knowledge reflects the environment in which our ancestors evolved (e.g., Campbell 1974).

Due to evolution, our perception and cognition are selective, and we can speak of perceptual biases that occur at three different levels: basic biases, which we share with higher vertebrates, biases that are characteristic of our species, and specific cultural perceptual biases. Similarly, our emotions have evolved since they have positively affected the survival and reproductive success of our ancestors ( $\mathrm{TO}^{-}$ oby, Cosmides 1990), indicating that humans respond emotionally to the world around them because they possess an aesthetic sense which is the product of evolution through natural selection. Studying both cognitive and emotional preferences can thus serve as a bridge between psychology and evolutionary theory (Kaplan 1987).

The universality of art in all known cultures indicates that aesthetics is also closely related to psychological adaptations (Tooby, Cosmides 2001). Aesthetic reasoning undoubtedly varies greatly over time and across cultures, but research shows that some basic algorithms are universal and have evolutionary origins (e.g., Brown 1991). Like physical characteristics, our cognitive structures are adaptations to solving the reproductive problems of the human phylogenetic past. This implies that evolutionary aesthetics is part of evolutionary psychology and rests on the premise that human basic aesthetic preferences have evolved in order to improve survival and reproductive success. In other words, evolutionary aesthetics is an attempt to understand the aesthetic reasoning of humans and their spontaneous differentiation between 'beautiful' and 'ugly' as a biologically adaptive capacity for making important decisions in life (see also Averill et al. 1998; Dutton 2003; Hartmann, Apaolaza-Ibanez 2010; Paden et al. 2012; Seghers 2015).

Probably the most famous example of evolutionary aesthetics is physical attraction in the context of mate selection, of which much has been discussed (e.g., Symons 1979), and the same logic can be applied to other visual preferences. In this paper, the emphasis is on landscapes and habitat selection preferences. The basic premise of evolutionary aesthetics in this domain is to show how people choose and want to reside in an environment where our species and ancestors evolved for millions of years.

We can differentiate among direct, indirect and vicarious (or symbolic) experiences of nature. It is obvious that in the modern world there has been a decline in direct experience of the natural environment, as it involves spontaneous contact with nature. Indirect experience represents organized contact with nature, where human intervention is seen (e.g., zoos, parks), and symbolic does not mean actual but mediated contact (books, movies, etc.). Thus, the growth in indirect and symbolic experience is noticeable and direct contact with nature has fallen dramatically. So the important question is whether and to what extent contact with natural systems and processes is important and useful for the well-being of today's humans, living in an environment that does not resemble the one in which our ancestors evolved.

\section{Habitat selection}

Humans receive a wealth of information from their surroundings on a daily basis, and it is impossible to assimilate and use all of it, while it is clear that most of this information has very little or no value to our survival. That is why natural selection has made us 
develop neural programs which assess information and act as filters that allow important data in and prevent irrelevant data from entering. These filters constitute biologically prepared learning that pays particular attention to decisions that affect survival and reproduction, which is why being attracted to certain environmental information is adaptive behaviour (Kaplan 1987). However, these decisions do not need to be adaptive today, since natural selection cannot affect our fit with future environments. For example, phobias that are almost universal in humans relate to snakes, spiders, heights, darkness and the like, all of which have had a major impact on survival and reproduction during most of human evolution, and not with the knives, automobiles, guns, and so on which are really more dangerous to human life in modern environments. As such, many phobias have to do with the environment in which human nature was formed, and they have managed to survive since then.

It is reasonable to assume that habitat selection is a process associated with human survival; that is, which has left consequences for the survival and reproduction of humans and their ancestors. Until the Neolithic and urban development, people mostly lived a nomadic and hunter-gatherer lifestyle, and the search and selection of habitats were of utmost importance not only for providing food and shelter, but also because habitats evoke certain emotions, stimulate environmental exploration, give sense of well-being and identity, etc. (Hunziker et al. 2007). Simply put, individuals who were able to find and identify a habitat that offered protection from predators and bad weather, while also enabling access to food, water, and other resources, were more successful than individuals who could not recognize such qualities in a given environment (Ruso et al. 2003). Of course, the preference for particular habitat types that facilitate adaptation is not unique to the human species alone, so habitat selection is widespread among vertebrates, and has been reported even in animals raised in the laboratory and without any prior experience with the natural environment (Kaplan 1987; see also Wecker 1964). Therefore, it can be said that habitat selection is an almost universal activity among animals that affects many choices of individual organisms.

Environmental preferences co-evolve with its qualities, meaning that organisms respond positively to environments where the chances of their survival and reproductive success are good (Orians, Wittenberger 1991). Likewise, organisms that choose to settle in less conducive environments leave fewer offspring. However, this correlation is not so simple, because a habitat which seems good at first glance may be inadequate due to other factors (such as infectious diseases, hidden predators, etc.), and organisms may have difficulty in truly, accurately or precisely assessing the quality of an environment (Orians, Wittenberger 1991). The habitat selection process itself takes place in stages - encounter, explore and exit or establish - and thus is a kind of hierarchical process that involves making several strategically important decisions.

The first stage begins with the arrival of the organism in an unknown general area, where there are several habitats that are suitable for various activities - some are for courtship, some for hunting, settling, etc. The organism must first decide whether or not a certain habitat should be explored or whether it should move on. This decision is largely based on the judgment of the distribution of objects in space, water, trees, or vegetation, shelter, potential distance from prey or a safe place, and the like. If an organism considers staying, then it goes into a more detailed exploration of the environment and then decides whether to stay or not, as well as whether that possible stay will be shorter or longer (Orians, Wittenberger 1991).

It is also clear that the key factor in this process is time, since better habitats are usually already occupied, which is why organisms have to make decisions very quickly - almost instinctively and often based on incomplete information. Contemporary habitat selection research shows that subjects do express their preferences relatively quickly and easily, but most often cannot explain their choices and are unaware of the predictive variables that make them prefer one environment rather than another, implying some automaticity in these choices (Kaplan 1987).

From an evolutionary perspective, there are many adaptive benefits to quick, automatic judgment of the information traits concerning a place or space we are approaching. Walking on varied terrain, choosing the right path, etc., require constant re-evaluation as the landscape opens up new vistas and opportunities. It is the information processing speed that is crucial for rapid response, which makes it appropriate to be automatic and unconscious, and to result in an affective (rather than cognitive) reaction (Ulrich 1983). In other words, it is not only important to rationally identify habitats that are useful, 
but also environments that we like emotionally. It is an effective guide to ongoing behaviour when an individual is intuitively (and aesthetically) attracted to promising places, or rejects unpromising ones.

Although today habitat selection is not a particularly important factor in human survival, this process was extremely significant for the everyday survival of our ancestors (Ruso et al. 2003). Therefore, the psychological mechanisms underlying habitat selection have been the subject of intense selection pressures, including the emergence of emotional reactions to certain environmental characteristics (Kaplan 1987; Seghers 2015). Because habitat selection has been crucial throughout human evolutionary history, research into this phenomenon, especially in the context of landscape preference, is of great importance for the general understanding of our evolved aesthetic tastes (Ruso et al. 2003).

\section{Biophilia and the evolutionary theories of land- scape preference}

Roughly speaking, two basic types of evolutionary aesthetics can be distinguished - evolutionary intuitionism and evolutionary cognitivism (Paden et al. 2012). Intuitionism speaks of fundamental aesthetic intuitions as adaptive preferences, meaning that the pleasures underlying aesthetic reasoning evolved because they played a role in adapting human beings to their environment. On the other hand, evolutionary cognitivism is based on remarks about the intrinsic beauty of (certain) living beings or landscapes; that is, the view that evolution brings about beautiful living forms, remarkable natural phenomena, and so on. Likewise, there are two paradigms when it comes to landscape preferences - objectivist and subjectivist (Lothian 1999; Maulan et al. 2006).

Objectivist approaches perceive visual quality as inherent in the landscape, while subjectivists claim that visual quality is a construct of the beholder. Within subjectivist approaches, positivist and phenomenological models exist - positivists analyse the physical and measurable features of landscapes, while phenomenological models focus on personal experience and meaning (Ohta 2001; Thwaites, Simkins 2007). It is just about what we attach the greater importance to, because it is indisputable that the landscape quality depends on both objective and subjective factors (Daniel, Vining 1983).

Thus, objectivists usually assume that there is a certain unchanging standard for aesthetic appreciation in the characteristics of the object itself (line, colour, form, etc.), and its proponents are most often artists, (landscape) architects, some physical geographers, ecologists and environmentalists, and others who claim aesthetic qualities of the object rest in its formal qualities independent of human perception and interpretation. Many of them also insist that aesthetic quality stems from 'naturalness', i.e. ecological diversity, and that unmodified or 'natural' landscapes are therefore of greater aesthetic value to humans. On these theoretical foundations, and the concept of 'natural' and 'picturesque', for example, Hyde Park in London was designed, with its curvilinear lines, vegetation masses and open vistas (Maulan et al. 2006).

On the other hand, subjectivist approaches emphasize that landscape aesthetics are the result of the interaction between the observer and object, which is why they focus on the cognitive and affective reactions of individuals. In this sense, the aesthetics of the landscape is a human construct on the socio-cultural or individual level, since it rests on the perception and interpretation by the human mind. In plain language, 'beauty is in the eye of the beholder'. It can be said that the objectivist paradigm often places people in a relatively peripheral position in which they, similar to a camera, passively 'capture' landscapes (like a work of art), while the subjectivist paradigm also takes into account the variables of human knowledge, experience, emotions, needs, etc. (Maulan et al. 2006.29-30).

The evolutionary theories that interest us in this paper imply that beauty or ugliness are not intrinsic features of objects, but that they arise from the $i n$ teraction between features of objects and the human nervous system. This indicates that for humans, beautiful objects are those that (accompanied by a positive reaction) improve our lives, in terms of increasing the chances of survival and reproduction. In contrast, ugly ones are those that impede certain aspect of our lives (Tooby, Cosmides 2001). If aesthetic preferences are the product of evolution, it follows that they are adaptations to the Pleistocene environment and not necessarily to the contemporary one, since the social environment in which we live today has existed for an extremely short time when viewed in the context of the evolution of the human species.

Therefore, there are Darwinist-oriented theories which explain landscape preferences as being the result of human evolution, implying that what we con- 
sider beautiful today is something that increased our ancestors' chances of survival. For this reason, even today, a great deal of the everyday aesthetic experience of humans involves a cognitive, emotional and behavioural response to landscapes in the immediate environment (Russo et al. 2003). In the following passages we will present the most significant evolutionary theories of landscape preferences and aesthetics, such as the prospect-refuge theory, savanna or habitat theory, information processing theory (or the mystery and complexity theory) and affective theory. They can all be linked to a more general framework called the biophilia hypothesis.

This hypothesis mainly relates to the claim that humans have a basic need to interact with 'nature' (Averill et al. 1998). As early as in his 1963 essay, Erich Fromm (Fromm 1963; Eckardt 1992) made a distinction between necrophilia (attraction to death or love of death) and biophilia (attraction to life or love of life). Fromm also mentions the biophilic personality type, which is typical of individuals who are surrounded by people who love life, security, justice and freedom. In a different sense, the term was revived and popularized by Edward 0. Wilson (1984; Kellert, Wilson 1993) who defines it as: "an innate tendency to focus on life and lifelike processes" (Wilson 1984.1), or an "innately emotional affiliation of human beings to other living organisms" (Wilson 1993.31). This would suggest that humans depend on nature, but not just for mere survival there are also aesthetic, intellectual and cognitive reasons why this relationship is significant. The essence of this idea is to explain the human biological need to maintain a relationship with life and lifelike processes, which is biologically based, so it represents the evolutionary heritage of our species.

Similar ideas can be found in the field of ecopsychology, which discusses ecological unconscious (Roszak 1992), and whose main purpose is to restore the connection between humans and nonhuman nature. It refers to the sense of interconnectedness between humans and other living beings, which stems from our ancient ancestors. Modern life usually prevents most people from understanding this connection, but Roszak points out that there is environmental reciprocity and that in some way we sympathize with planet Earth.

In the context of this paper, the most important question is whether human physical and mental well-being depends on contact with natural systems and processes (or not), primarily because humans throughout their history lived in environments that were not altered to the extent those they are living in today are altered. Usually, the social dimension of the world is cited as the key environment in which humans evolved, and while no one denies the importance of social interactions and sociality ( $\breve{S} k o r i c$, Kišjuhas 2015), the importance of vegetation, landscape, the living world (plants and animals), wind, rain, smells, sounds, etc., must not be omitted. This is not to say that biophilia, like an instinct, is rigidly encoded in our genome, but a kind of weak biological tendency, a set of predispositions for gaining certain preferences. It is simply a part of human nature that was formed in an evolutionary environment (including the physical environment) through biocultural evolution, and therefore depends on learning, experience and culture (Boyd, Richerson 2005).

When it comes to landscape preferences, probably the most important question is the one concerning the cognitive mechanisms involved in the process. The most commonly mentioned mechanism is similar to the ethological construct of the innate schemata, which is a mental image of the ideal landscape that represents the standard of judgment. Theoretical differences generally exist when it comes to the essence of that image - be it a landscape in which humans evolved (such as savanna), or perhaps any type of landscape containing those features that promote fitness. In this sense, among the first evolutionary theories of landscape preference that stands out is what was then called habitat theory by Jay Appleton (1975), now known as prospect-refuge theory. He was one of the earliest to suggest the provocative idea that a preference for a particular type of landscape is part of our evolved heritage, and that the environment should be viewed in functional rather than morphological frames. Beauty (landscape) is not found neither in beautiful objects, nor in the eyes of the beholder, but in the (functional) relationship between the individual and environment.

In this regard, aesthetic satisfaction comes from the fact that the observer sees an environment as beautiful or useful for fulfilling his or hers biological needs. The possibility of "seeing and not being seen" satisfies many such needs, as previously written by Konrad Lorenz (1949/1952). Therefore, Appleton claims that the key components of landscape preferences are 'prospect' (having a grand view, overview or opportunity) and 'refuge' (having a safe place to hide or safety). For example, closed forests are not good for prospect and deserts are not good for refuge, while savannas offer a good combination 
of these elements. Aesthetically most attractive and pleasing are landscapes that have a balance between prospect and refuge components - elevated landforms (due to the overall view of the landscape in search of food, water and prey) and attributes such as groupings of trees (due to safety factors), with open spaces and fresh water (see also Maulan et al. 2006). Appleton argues that such evolved preferences apply today, regardless of the fact that most people no longer have to seek shelter from predators.

However, it can be said that his theory deals only with a limited part of the otherwise very complex judgments that people make about their environment (Heerwagen, Orians 1993). Appleton looks only at the initial evaluation and exploration of unfamiliar environments and focuses on the opportunities to acquire information, as well as the security that can(not) be achieved, while the habitat selection process is usually much more complex. Some empirical tests confirm his theory (e.g., Clamp, Powell 1982; Mealey, Theis 1995) and other do not (e.g., Klopp, Mealey 1998). There are not many studies examining the balance between prospect and refuge, since it is very difficult to analyse - for example, it is not clear whether darkness counts as prospect or refuge (Bunkse 1977), and this theory is indeed quite reductionist and extreme (Ulrich 1983). That is why Appleton later (Appleton 1990) tried to modify the theory, although to date there is still not much convincing evidence to support it.

The next influential evolutionary theory is commonly called the savanna hypothesis or savanna theory, and it also rests on assumptions concerning the search for a suitable habitat (Orians 1980; 1986; Orians, Heerwagen 1992). Gordon Orians argues that humans have an innate preference for environments that are similar to the African savannas, because it was not only the habitat of our distant ancestors, but also the spatial context of hominid evolution, which is why they evolved a preference for environments of similar appearance. At the same time, it is argued that the (evolved) preference for savannas (i.e. environments containing grasslands and scattered trees with water nearby) offered an evolutionary advantage to hunter-gatherers, which is complementary to the prospect-refuge theory ( $A P$ pleton 1975).

These open landscapes also offered benefits for exploring the environment, as well as the highest concentration of resources for early humans and species before them. This microenvironment allowed hu- mans to survive because they had food, a resting place, shelter from predators, sun shade and nearby animals that could be hunted (see also Seghers 2015). Some studies show that in many countries around the world people arrange their landscapes to resemble natural savanna landscapes, i.e. as a mix of open grassland and groups of trees, just as savanna-like landscapes appear on many paintings, calendars and (desktop) wallpapers (Orians 1980; see also Heerwagen, Orians 1993; Hunziker et al. 2007).

However, this theory also has its critics, who claim that human ancestors began to settle in non-savanna environments millions of years ago, which actually left them plenty of time to evolve aesthetic preferences toward different environments too (Diamond 1993). When it comes to more empirical research, some authors offer limited support for the human savanna tendency, which has been confirmed in children between the ages of eight and eleven ( $\mathrm{Bal}$ ling, Falk 1982), while other research has not confirmed this hypothesis (e.g., Lyons 1983).

The third relevant evolutionary theory of landscape preference is the one that asserts factors such as mystery and complexity, or the so-called information processing theory (Kaplan 1987; Kaplan, Kaplan 1989). Like Appletone, Stephen and Rachel Kaplan point to two basic human needs that influence aesthetic appreciation of landscape - the need for exploration and for understanding. They claim that human ancestors who depended on hunting and gathering had to explore new areas, but also to understand them. This is why these authors apply the information processing approach to landscape aesthetics in order to explain human-landscape interactions, stating that people are trying (and striving) to make sense of the environment through four predictor variables: (1) coherence (immediate understanding of the fit and harmony of elements in the environment), (2) complexity (visual wealth that can be directly explored), (3) legibility (understanding of what we see and the ability to find a way and not to get lost), and (4) mystery (the existence of new things to explore if we go deeper and further into the landscape). Two variables help us understand the environment (coherence and legibility), while the other two (complexity and mystery) inspire us to explore it and influence our (landscape) aesthetic preferences.

For example, there is some regularity in preferences, even when it comes to nature scenes in photographs 
(Kaplan et al. 1972). The most positively evaluated scenes were those that "(1) contained a trail that disappeared around the bend, (2) depicted a brightly lit clearing, partially obscured from view by intervening foliage" (Kaplan 1987.8), suggesting that the most popular images 'promise' more information. For these reasons, this predictor is also called 'mystery', while some characteristics such as coherence or complexity are much less significant. The explanation for this phenomenon is based on a claim concerning the adaptive function of human curiosity - humans prefer those environments that facilitate the acquisition of new information, i.e. those where new information can be obtained if the environment is explored.

Mystery, then, is primarily about the expectation that a deeper encroachment into the landscape enables access to additional and new information, as a balance between what is seen and what is anticipated. It is assumed that the survival of the human species depended on the development of cognitive information processing skills that have further developed into a preference for the landscapes which made sense for humans. Joachim Wohlwill also explored the assessment of non-representational art, urban and rural scenes, and natural landscapes with an emphasis on elements of complexity (colours, shapes, textures, etc.) (Wohlwill 1968), and the data indicated that individuals mostly preferred images of moderate complexity.

Finally, the affective theory by Roger Ulrich (1977; 1983; 1986) claims that natural environments and landscapes give rise to emotional states of well-being in humans that can be measured. He also analysed the information features of different landscapes and identified the following five significant variables: focality (coherence, unity), ground surface texture, depth, mystery and complexity. However, Ulrich notes that affective reactions to certain visual configurations of these variables have had adaptive value during human evolution, which is why people still prefer them today, even without cultural learning or socialization. The important emotions in this regard are pleasantness, calm, exhilaration, caution, fear and anxiety. It is a model that contrasts with Kaplans' cognitive theory, because it is based on the idea that emotional reactions to landscapes occur before cognitive information processing (Zajonc 1980), as well as the thesis that positive emotions have a beneficial effect on survival. In addition, Ulrich further (Ulrich 1979; 1984; 1993) investigated emotional responses to urban and natural landscapes, where the results suggested that urban scenes evoke more negative emotions.

Of course, in addition to evolutionary theories, there are numerous cultural theories that explain landscape preferences through the process of learning and influence of social, cultural and personal factors. In other words, aesthetic preferences are understood as social constructs, as it is thought that humans have repeatedly adapted to different habitats and are very flexible when it comes to responding to them. Here, the cognitive assessment of the functions offered to individuals by a landscape is emphasized, rather than the immediate affective response (Bell 1999).

The best known are the cultural theories highlighting topophilia and ecological aesthetics. Topophilia refers to the fact that people tend to bond with what they know well, which means landscape preference is influenced primarily by familiarity and experience (Tuan 1974). The second group of theories emphasizes the importance of knowledge about ecological functions, and that knowledge leads to the preferences for a landscape (Carlson 2009; Gobster 1999). Another group of theories speaks of genius loci (meaning a specific atmosphere of a place), and thus the unique and visually striking features and characteristics of landscapes (Bell 1999). Still another group of cultural theories notes the importance of landscape heritage, where there are visual cues of cultural heritage (Fairclough et al. 1999), while the aesthetics of care foregrounds the importance of signs indicating some concern about the landscape (Nassauer 1992). There is not necessarily a contradiction or a discrepancy between evolutionary and cultural theories, as evidenced by the conclusions of some empirical research.

\section{Applied empirical research and biophilic de- sign}

Numerous empirical studies show that aesthetically beautiful and attractive habitats for humans are the ones in which the evolution of our ancestors took place, and children also mainly favour savannas, landscapes with clouds and water, open spaces with trees that fork near the ground, which offer lowhanging fruits and the like. For most people, running water is more attractive than stagnant water, remote mountains are more attractive than flat terrain, and the most preferred are landscapes that are relatively open and smooth with wide horizons, low and homogeneous vegetation and scattered trees 
(with a round shape), clouds, game animals and the like (Calvin et al. 1972; Kaplan et al. 1972; Balling, Falk 1982; Kaplan, Kaplan 1989; Orians, Heerwagen 1992; Purcell et al. 1994; Summit, Sommer 1999; Hartmann, Apaolaza-Ibanez 2010; Dutton 2003; Thornhilll 1998; 2003).

For example, in perhaps the most famous empirical study of this type (Balling, Falk 1982), a sample consisting of 548 very different respondents (elementary school students, college students, the elderly, professional foresters, biology teachers, etc.) were shown five different biomes on slides (tropical forest, desert, savanna, deciduous and coniferous forest, and without images of water, animals, humans or human intervention), and subjects under the age of 15 clearly displayed a preference for savanna-like environments. For these reasons, it can be said that there is limited support for the savanna hypothesis (Orians 1980, 1980), due to the long evolutionary history of human life in the savanna, which is best expressed in childhood. The preference for savannas decreases with age and experience, and a preference for the most familiar environments increases (Balling, Falk 1982.25). This suggests that familiarity in terms of growing up and living close to a (different) natural environment probably modifies the initial preferences for savannas (Lyons 1983).

On the other hand, in a recent study of 750 subjects and with images of 13 different biomes (savanna trees, Canadian trees and lakes, birch trees in Europe, eucalyptus trees in Australia, an urban environment, desert, etc.), the hypothesis of an innate human propensity for savannas was not corroborated, but it was confirmed for lush green landscapes with a source of water and generally familiar biomes (Hartmann, Apaolaza-Ibanez 2010). These researchers therefore conclude that while an evolutionary approach to landscape preferences is important, limiting it to hunter-gatherer periods in the $\mathrm{Pa}$ laeolithic or the African savanna probably does not capture all the dynamics of human behavioural evolution. However, the mentioned familiarity effect was confirmed (see also Herzog et al. 2000), where central European mountains or the Mediterranean coast are preferred over, for example, Australian eucalyptus shrubs. The concrete application of the results of this research concerns the domain of advertising, that is, the claim of a more positive influence of those commercials representing 'natural' scenes with the favoured biosphere, than those with, for example, urban environments or deserts without vegetation.
In an effort to demonstrate the savanna hypothesis, however, additional research has been conducted among individuals living in the rainforest belt of $\mathrm{Ni}$ geria (Falk, Balling 2010). After presenting five biomes (rainforest, deciduous forest, evergreen forest, desert and savanna), these subjects selected the savanna as the most suitable place to live. In addition, the analysis of particular historical patterns of landscape design (private gardens, urban parks, etc.) indicates certain universal characteristics or parallels, such as savanna-like combinations of short grass and scattered trees (Falk, Balling 2010.479). The results of this study suggest that humans, regardless of their background and experience, are likely to start life with a preference for savanna-like environments.

Similarly, in a cross-cultural study of tree preferences (Orians, Heerwagen 1992), the respondents selected as the most attractive trees the ones most resembling trees from the East African savanna. Specifically, people prefer trees with lower trunks (easier to climb), with moderate canopy density (allowing a balance between hiding and not being able to see out), with high degrees of canopy layering (greater opportunities for viewing out) and a broader tree canopy relative to its height (because it can accommodate more people on branches). Large canopies, short trunks or acacia trees, typical of the African savanna, are also preferred over oak, conifers, palm trees or eucalyptus (Summit, Sommer 1999). A detailed analysis of landscape features in Western painting (Heerwagen, Orians 1993) also demonstrated a human propensity for savanna-like environments.

Theoretical and empirical knowledge of landscape preferences can be applied in the context of environmental education (Swonke 2000). Specifically, biophilic feelings, as well as aesthetic preferences for certain elements of the natural environment, can serve to nourish the desire for environmental protection, that is, the development of the conservation ethic (Wilson 1993). However, it is important to understand that mere contact or direct experience with nature does not automatically lead to biophilia or 'love' for nature, and especially not to the preservation of the natural environment (Swonke 2000). Some authors have empirically investigated the human tendency for fractals, i.e. those geometric shapes that can be divided into parts that simultaneously resemble the original shape (Hagerhall et al. 2004). Fractals are relatively common in nature and these authors claim that the most preferred are landscapes in the mid-range (of complexity) related to 
fractal dimension, which are landscapes that also correspond to savannas.

However, perhaps the most important application of this knowledge concerns human health. Research shows that preferred landscapes arouse positive emotions and that even the pulse rate decreases when observing natural (but not urban) landscapes (Laumann et al. 2003). Furthermore, after surgery patients who have a view of a natural landscape recover better and faster (Ulrich 1983; 1984; Fuller et al. 2007; Grahn, Stigsdotter 2003; Kaplan 1995; Parsons et al. 1998; Rappe, Kivelä 2005).

Considering the evolutionary aesthetics and theories of landscape preferences, highly illustrative is the project The People's Choice, realized by the artists Vitaly Komar and Alexander Melamid in 1993 (Wypijewski 1997). In collaboration with opinion polling agencies, and while deliberately avoiding the word 'art', they explored the aesthetic preferences of people from eleven countries from different continents. It was meant in part as an artistically ironic commentary on popular tastes, but also on political systems that rely too heavily on polls and popular opinion surveys when making decisions (Hillings 1999).

It turned out that the respondents' favourite colour was blue and their second favourite was green, that people preferred realistic images depicting water, trees and other plants, clouds, people (primarily women, children and historical figures) and animals (especially large mammals, domestic and wild), which is highly consistent with the evolutionary theories of (landscape) aesthetic preferences (Dutton 2003). Finally, it is particularly interesting that, based on these popular responses, the artists Komar and Melamid actually painted the image that incorporated all the highest-rated elements from their research for each country.

In the case of the United States, it was (a rather 'kitschy') blue-green $19^{\text {th }}$ century realist landscape, featuring children, deer, and George Washington (Fig. 1). With certain cultural-specific exceptions (e.g., Russians chose Jesus Christ instead of George Washington as their favoured historical figure), a very similar pattern was observed in other societies, which is why the authors conclude that it is a "universal model for the paintings that people want" (Hillings 1999.60). In a more contemporary context, it is also interesting to refer to the famous default computer desktop wallpaper for the Windows XP operating system, a photograph of a green hill and blue sky with clouds (from Sonoma County, California), conspicuously named 'Bliss', and which can be considered as one of the most viewed photographs in the 2000s (Fig. 2). On the other hand, this extremely popular image still lacks people, animals, and especially trees (in the sense of refuge).

Some research (e.g., Kaplan et al. 1972) clearly shows that people often prefer images of the natural over the built environment, and that out of the latter the most attractive image is that of an urban park, the lowest ranked of the 'natural' images. Biophilic design or architecture is built on these bases, and it emphasizes the importance of one's experience of nature in the built environment which takes into account the ethics of environmental sustainability (Söderlund 2019). In other words, it is an attempt to reintegrate people with the natural environment after a long time: "the expression of the inherent human need to affiliate with nature in the design of the built environment" (Kellert, Heerwagen 2008.viii). There is also the idea of biophilic cities, which are not the same as green cities, since the mere presence of nature is not enough. In biophilic cities, people are directly and actively involved in various processes, such as learning about nature, enjoying it or taking care of it, and developing emotional bonds towards it (Beatley 2011; Kellert et al. 2008).

Biophilic design can thus be organic and vernacular. Organic design is based on theory and research on

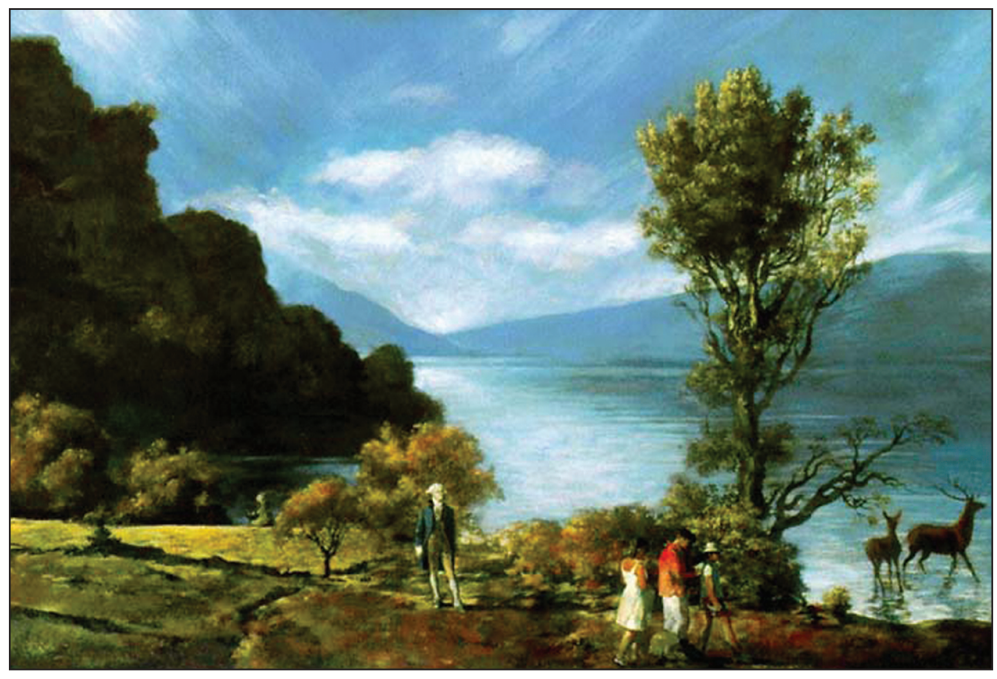

Fig. 1. Komar and Melamid, "America's Most Wanted", 1994. Oil and acrylic on canvas. 
how humans respond positively to natural materials, lighting and shapes, and the main goal of biophilic architecture is to maximize well-being while minimizing ecological impact. Vernacular design, on the other hand, aims to awaken a sense of connection to place (see also Hunziker et al. 2007), which at the same time might create a desire within a certain community to care for a particular bioregion. Environmental psychology also speaks of the tendency of people to create and develop a kind of attachment with specific locations. This attachment can then relate to our immediate environment, such as our home, but also to the neighbourhood, city or even the region. However, place attachment does not necessarily have to do with behaviour that takes care of nature in general, so in addition to the undoubted importance of the environment for survival, evolutionary theories must also take into account the emotional bonds between people and place. There is no doubt that place can be meaningful for humans, and that the aesthetics of survival is not enough to fully explain one's environmental preferences.

\section{Why the aesthetics of survival is not enough}

Philosophical aesthetics is not threatened by an unjustified reduction to evolutionary biology, psychology or neurobiological explanations, while evolutionary disciplines and humanities may be complementary in understanding the human sense of beauty (Seghers 2015). Referring to the evolution of adaptive mechanisms in the context of habitat selection, theory and research in the field of evolutionary aesthetics can explain why certain objects and/ or landscapes cause certain neural rewards and, therefore, a positive aesthetic appreciation. Aesthetic reactions are also a guide to human behaviour, in-

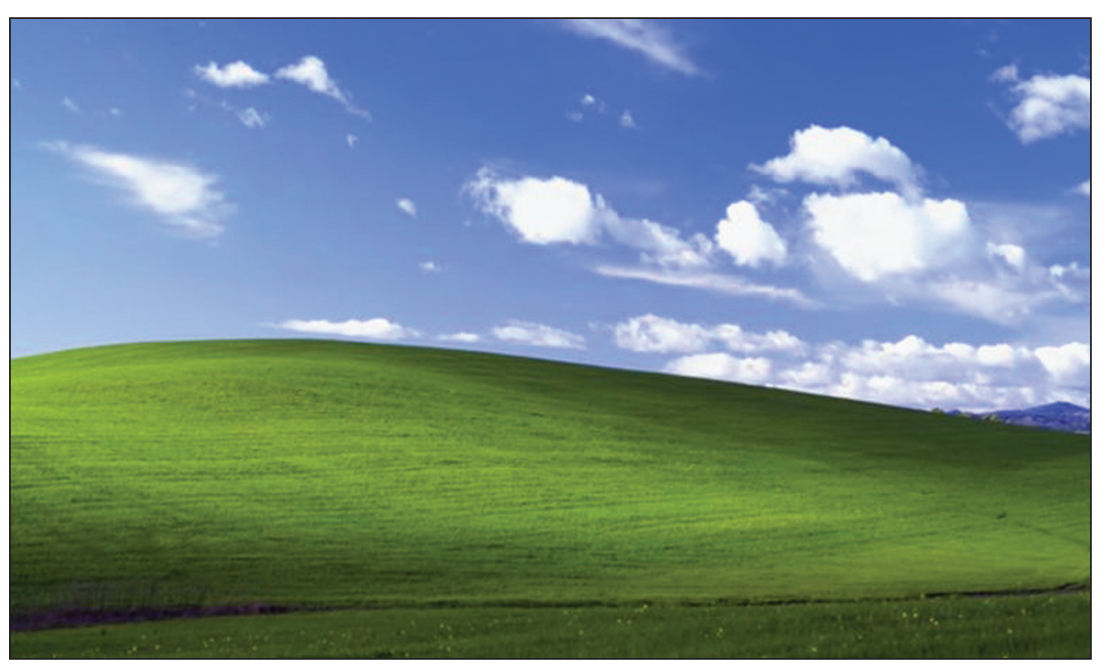

Fig. 2. Charles O'Rear, "Bliss", 1996. Landscape photography. cluding everyday behaviour with many practical consequences, such as organizing work and living spaces, but also in the domains such as health, design, marketing, education, environmental protection and the like, as previously discussed.

Every person has aesthetic preferences, but they are not exclusively random or individual. There are universal and biophilic preferences for open grasslands, trees, fresh water or symmetrical structures, as well as antipathy or disgust for spiders and snakes, which is called biophobia (Orr 1993; Ulrich 1993). All this points to the phylogenetic basis of aesthetic reasoning that existed before the evolution of human culture and to the validity of evolutionary explanations. In this sense, aesthetic reactions are not a trivial aspect of 'the human makeup', nor is aesthetics a 'whim' that people engage in at leisure (Kaplan 1987.26). Simply put, innate aesthetic biases helped individuals to behave and act in an adaptive way (Swonke 2000.260).

We have seen that numerous studies point to the universality of landscape preferences, but it should not be forgotten that these preferences can nevertheless be modified by cultural influences and experiences, so it is not surprising that there are differences in preferences either across (sub)cultures or social groups (Tveit 2009). Neither biological nor cultural reductionism is adequate, that is, biological or social factors alone are not sufficient to explain the individual aesthetic experience. It is not disputed that landscapes are biologically important to humans and evoke certain (aesthetic) emotions, but they are also sometimes important for one's identity and well-being, namely, for transforming mere habitable space into a true living place (Hunziker et al. 2007).

The bottom line is that it is not enough to take care solely of survival, as well-being must also be taken into account. Still, it is critical to note and discern the so-called primitive preferences which are built on human attachment to nature, while in addition to the importance of (biophilic) design for the body, the senses must not be ignored. Therefore, an adequate and desirable environment is one that takes into account 
the physiological, mental and social aspects, and that would be the evolutionary environments of the species. They meet not only survival needs, but also one's well-being needs, which relate to the quality and psychological aspects of human life (Boyden 1971; Hildebrand 1999).

\section{ACKNOWLEDGEMENTS}

This paper was written as a part of project no. 179037 which is financed by the Ministry of Education, Science and Technological Development of Republic of Serbia.

\section{References}

Appleton J. 1975. The Experience of Landscape. Wiley. London.

1990. The Symbolism of Habitat: An Interpretation of Landscape in the Arts. University of Washington Press. London.

Averill J. R., Stanat P., and More T. A. 1998. Aesthetics and the environment. Review of General Psychology 2(2): 153-174.

Balling J. D., Falk J. H. 1982. Development of visual preference for natural environments. Environment and Behavior 14(1): 5-28.

Beatley T. 2011. Biophilic Cities: Integrating Nature in to Urban Design and Planning. Island Press. Washington.

Bell S. 1999. Landscape: Pattern, Perception and Process. E \& FN Spon. London.

Boyd R., Richerson P. J. 2005. The Origin and Evolution of Cultures. Oxford University Press. New York.

Boyden S. 1971. Biological determinants of optimal health. In D. J. M. Vorster (ed.), The Human Biology of Environmental Change. Proceedings of a conference held in Blantyre, Malawi, 5-12 April 1971. International Biological Programme. 7 Marylebone Road. London: 3-11.

Brown D. 1991. Human Universals. McGraw-Hill. New York.

Bunkse E. V. 1977. The Experience of Landscape (Book review). Annals of the American Association of Geographers 67(1): 149-151.

Calvin J. S., Dearinger J. A., and Curtin M. E. 1972. An attempt at assessing preferences for natural landscapes. $\mathrm{En}$ vironment and Behavior 4(4): 447-470.

Campbell D. T. (1974). Evolutionary epistemology. In P. A. Schilpp (ed.), The Philosophy of Karl Popper, 2 vols. Open Court. La Salle: 413-463.
Carlson A. 2009. Nature and Landscape: An Introduction to Environmental Aesthetics. Columbia University Press. New York.

Clamp P., Powell M. 1982. Prospect-refuge theory under test. Landscape Research 7(3): 7-8.

https://doi.org/10.1080/01426398208706036

Daniel T. C., Vining J. 1983. Methodological issues in the assessment of landscape quality. In I. Altman, J. F. Wohlwill (eds.), Behavior and the Natural Environment. Plenum Press. New York: 39-84.

Degler C. N. 1991. In Search of Human Nature: The Decline and Revival of Darwinism in American Social Thought. Oxford University Press. New York.

Diamond J. 1993. New Guineans and their natural world. In S. R. Kellert, E. O. Wilson (eds.), The Biophilia Hypothesis. Island Press. Washington: 251-270.

Dissanayake E. 1992. Homo Aestheticus: Where Art Comes From and Why. Free Press. New York.

Dutton D. 2003. Aesthetics and evolutionary psychology. In J. Levinson (ed.), The Oxford Handbook for Aesthetics. Oxford University Press. New York: 693-705.

Eckardt M. H. 1992. Fromm's concept of biophilia. Journal of the American Academy of Psychoanalysis 20(2): 233240. https://doi.org/10.1521/jaap.1.1992.20.2.233

Fairclough G., Lambrick G., and McNab A. 1999. Yesterday's World, Tomorrow's Landscape. The English Heritage Historic Landscape Project 1992-1994. English Heritage. London.

Falk J. H., Balling J. D. 2010. Evolutionary influence on human landscape preference. Environment and Behavior 42(4): 479-493.

https://doi.org/10.1177/0013916509341244

Fromm E. 1963. War Within Man: A Psychological Enquiry Into the Roots of Destructiveness. American Friends Service Committee. Philadelphia. 
Fuller R. A., Irvine, K. N., Devine-Wright, P., Warren P. H., and Gaston K. J. 2007. Psychological benefits of green space increase with biodiversity. Biology Letters 3(4): 390-394. https://doi.org/10.1098/rsbl.2007.0149

Gobster P. H. 1999. An ecological aesthetic for forest landscape management. Landscape Journal 18(1): 54-64. https://doi.org/10.3368/lj.18.1.54

Grahn P., Stigsdotter U. A. 2003. Landscape planning and stress. Urban Forestry and Urban Greening 2(1): 1-18. https://doi.org/10.1078/1618-8667-00019

Hagerhall C. M., Purcell T., and Taylor R. 2004. Fractal dimension of landscape silhouette outlines as a predictor of landscape preference. Journal of Environmental Psycho$\operatorname{logy} 24(2): 247-255$.

https://doi.org/10.1016/j.jenvp.2003.12.004

Hartmann P., Apaolaza-Ibanez V. 2010. Beyond savanna: An evolutionary and environmental psychology approach to behavioral effects of nature scenery in green advertising. Journal of Environmental Psychology 30(1): 119- 128. https://doi.org/10.1016/j.jenvp.2009.10.001

Heerwagen J. H., Orians G. H. 1993. Humans, habitats, and aesthetics. In S. R. Kellert and E. O. Wilson (eds.), The Biophilia Hypothesis. Island Press. Washington: 138-172.

Herzog T. R., Herbert, E. J., Kaplan R., and Crooks C. L. 2000. Cultural and developmental comparisons of landscape perceptions and preferences. Environment and Behavior 32(3): 323-346.

https://doi.org/10.1177/001391650032300

Hildebrand G. 1999. Origins of Architectural Pleasure. University of California Press. Berkeley.

Hillings V. L. 1999. Komar and Melamid's dialogue with (art) history. Art Journal 58(4): 48-61. http://www.jstor.com/stable/777911

Hunziker M. Buchecker M., and Hartig T. 2007. Space and place - Two aspects of the human-landscape relationship. In F. Kienast, O. Wildi and S. Ghosh (eds.), A Changing World, Landscape Series (vol. 8). Springer. Dordrecht: 47-62.

Kaplan R. Kaplan S. 1989. The Experience of Nature: $A$ Psychological Perspective. Cambridge University Press. New York.

Kaplan S. 1987. Aesthetics, affect, and cognition: Environmental preference from an evolutionary perspective. $E n$ vironment and Behavior 19(1): 3-32.

https://doi.org/10.1177\%2F0013916587191001

1995. The restorative benefits of nature: Toward an integrative framework. Journal of Environmental Psy- chology 15(3): 169-182.

https://doi.org/10.1016/0271-4944(95)90001-2

Kaplan S., Kaplan R., and Wendt J. S. 1972. Rated preference and complexity for natural and urban visual material. Perception and Psychophysics 12(4): 354-356. https://doi.org/10.3758/BF03207221

Kellert S. R., Heerwagen J. H. 2008. Preface. In S. R. Kellert, J. H. Heerwagen and M. L. Mador (eds.), Biophilic Design: The Theory, Science, and Practice of Bringing Buildings to Life. John Wiley \& Sons: Hoboken: vii-ix.

Kellert S. R., Heerwagen J. H., and Mador M. L. (eds.) 2008. Biophilic Design: The Theory, Science, and Practice of Bringing Buildings to Life. John Wiley \& Sons. Hoboken.

Kellert S. R., Wilson E. O. (eds.) 1993. The Biophilia Hypothesis. Island Press. Washington.

Klopp B., Mealey L. 1998. Experimental mood manipulation does not induce change in preference for natural landscapes. Human Nature 9(4): 391-399.

https://doi.org/10.1007/s12110-998-1016-z

Laumann K., Garling T., and Stormark K. M. 2003. Selective attention and heart rate responses to natural and urban environments. Journal of Environmental Psychology 23(2): 125-134.

https://doi.org/10.1016/S0272-4944(02)00110-X

Lorenz K. 1949/1952. King Solomon's Ring. Methuen. London.

Lothian A. 1999. Landscape and the philosophy of aesthetics: Is landscape quality inherent in the landscape or in the eye of the beholder? Landscape and Urban Planning 44(4): 177-199.

https://doi.org/10.1016/S0169-2046(99)00019-5

Lyons E. 1983. Demographic correlates of landscape preference. Environment and Behavior 15(4): 487-511. https://doi.org/10.1177/0013916583154005

Maulan S., Shariff M. K. M., and Miller P. A. 2006. Landscape preference and human well-being. ALAM CIPTA, International Journal on Sustainable Tropical Design Research \& Practice 1(1): 25-32.

http://psasir.upm.edu.my/id/eprint/2435

Mealey L., Theis P. 1995. The relationship between mood and preferences among natural landscapes: An evolutionary perspective. Ethology and Sociobiology 16(3): 247256. https://doi.org/10.1016/0162-3095(95)00035-J

Nassauer J. I. 1992. The appearance of ecological systems as a matter of policy. Landscape Ecology 6(4): 239-250. 
Ohta H. 2001. A phenomenological approach to natural landscape cognition. Journal of Environmental Psycho$\operatorname{logy} 21(4)$ : 387-404.

https://doi.org/10.1006/jevp.2001.0233

Orians G. H. 1980. Habitat selection: General theory and applications to human behaviour. In J. S. Lockard (ed.), The Evolution of Human Social Behaviour. Elsevier. New York: 49-66.

1986. Ecological Knowledge and Environment Problem-solving: Concepts and Case Studies. National Academic Press. Washington.

Orians G. H., Wittenberger J. F. 1991. Spatial and temporal scales in habitat selection. The American Naturalist 137 (Supplement: Habitat Selection): S29-S49. www.jstor.org/stable/2462287

Orians G. H., Heerwagen J. H. 1992. Evolved responses to landscapes. In J. H. Barkow, L. Cosmides and J. Tooby (eds.), The Adapted Mind: Evolutionary Psychology and the Generation of Culture. Oxford University Press. New York: 555-579.

Orr D. W. 1993. Love it or lose it: The coming biophilia revolution. In S. R. Kellert and E. O. Wilson (eds.), The Biophilia Hypothesis. Island Press. Washington: 415-440.

Paden R., Harmon L. K., and Milling C. R. 2012. Ecology, evolution, and aesthetics: Towards an evolutionary aesthetics of nature. British Journal of Aesthetics 52(2): 123-139. https://doi.org/10.1093/aesthj/ays001

Parsons R., Tassinary, L. G., Ulrich, R. S., Hebl M. R., and Grossman-Alexander M. 1998. The view from the road: Implication for stress recovery and immunization. Journal of Environmental Psychology 18(2): 113-140. https://doi.org/10.1006/jevp.1998.0086

Purcell A. T., Lamb, R. J., Peron E. M., and Falchero S. 1994. Preference or preferences for landscape? Journal of Environmental Psychology 14(3): 195-209. https://doi.org/10.1016/S0272-4944(94)80056-1

Rappe E., Kivelä S. 2005. Effects of garden visits on longterm care residents as related to depression. HortTechno$\log y$ 15(2): 298-303.

https://doi.org/10.21273/HORTTECH.15.2.0298

Roszak T. 1992. The Voice of the Earth: An Exploration of Ecopsychology. Touchstone Books. New York.

Ruso B., Renninger L., and Atzwanger K. 2003. Human habitat preferences: A generative territory for evolutionary aesthetics research. In E. Voland, K. Grammer (eds.), Evolutionary Aesthetics. Springer. Berlin: 279-294.
Segerstråle U. 2000. Defenders of the Truth: The Battle for Science in the Sociobiology Debate and Beyond. Oxford University Press. New York.

Seghers E. 2015. Of Darwin and other demons: The evolutionary turn in aesthetics. Kultura - Spoteczeństwo Edukacja 2(8): 73-90.

https://doi.org/10.14746/kse.2015.2.5

Söderlund J. 2019. The Emergence of Biophilic Design. Springer. Cham.

Summit J., Sommer R. 1999. Further studies of preferred tree shapes. Environment and Behavior 31(4): 550-576.

Swonke B. 2000. Visual preferences and environmental protection: Evolutionary aesthetics applied to environmental education. Environmental Education Research 6(3): 259-267. https://doi.org/10.1080/713664681

Symons D. 1979. The Evolution of Human Sexuality. Oxford University Press. New York.

Škorić M., Kišjuhas A. (2015). Magic social numbers: On the social geometry of human groups. Anthropos 110(2): 489-501. https://doi.org/10.5771/0257-9774-2015-2-489

Thornhill R. 1998. Darwinian aesthetics. In C. Crawford, D. Krebs (eds.), Handbook of Evolutionary Psychology: Ideas, Issues and Applications. Lawrence Erlbaum Associates. Mahwah: 543-572.

2003. Darwinian aesthetics informs traditional aesthetics. In E. Voland and K. Grammer (eds.), Evolutionary Aesthetics. Springer. Berlin and Heidelberg: 9-35.

Thwaites K., Simkins I. 2007. Experiential Landscape. Routledge. London.

Tooby J., Cosmides L. 1990. The past explains the present: Emotional adaptations and the structure of ancestral environments. Ethology and Sociobiology 11(4-5): 375-424.

1992. The psychological foundations of culture. In J. Barkow, L. Cosmides, and J. Tooby (eds.), The Adapted Mind: Evolutionary Psychology and the Generation of Culture. Oxford University Press. New York: 19-136.

2001. Does beauty build adapted minds? Toward an evolutionary theory of aesthetics, fiction and the arts. SubStance 30(94/95): 6-27.

https://www.jstor.org/stable/3685502

Tuan Y. 1974. Topophilia. PrenticeHall. Englewood Cliffs.

Tveit M. S. 2009. Indicators of visual scale as predictors of landscape preference: A comparison between groups. Jour- 
nal of Environmental Management 90(9): 2882-2888. https://doi.org/10.1016/j.jenvman.2007.12.021

Ulrich R. S. 1977. Visual landscape preference: A model and application. Man-Environment Systems 7(5): 279293.

1979. Visual landscapes and psychological well-being. Landscape Research 4(1): 17-23.

1983. Aesthetic and affective response to natural environment. In I. Altman, J. F. Wohlwill (eds.), Human Behaviour and Environment: Advances in Theory and Research. Plenum Press. New York: 85-125.

1984. View through a window may influence recovery from surgery. Science 224(4647): 420-421. https://doi.org/10.1126/science.6143402

1986. Human responses to vegetation and landscapes. Landscape and Urban Planning 13: 29-44. https://doi.org/10.1016/0169-2046(86)90005-8

1993. Biophilia, biophobia and natural landscapes. In S. R. Kellert, E. 0. Wilson (eds.), The Biophilia Hypothesis. Island Press. Washington: 73-137.
Wecker S. C. 1964. Habitat selection. Scientific American 211(4): 109-116.

Wilson E. 0. 1978. On Human Nature. Cambridge: Harvard University Press.

1984. Biophilia: The Human Bond with Other Species. Harvard University Press. Cambridge and London.

1993. Biophilia and the conservation ethic. In S. R. Kellert, E. O. Wilson (eds.), The Biophilia Hypothesis. Island Press. Washington: 31-41.

Wohlwill J. F. 1968. Amount of stimulus exploration and preference as differential functions of stimulus complexity. Perception and Psychophysics 4(5): 307-312. https://doi.org/10.3758/BF03210521

Wypijewski J. (ed.) 1997. Painting by Numbers: Komar and Melamid's Scientific Guide to Art. Farrar, Straus \& Giroux. New York.

Zajonc R. B. 1980. Feeling and thinking: Preferences need no inferences. American Psychologist 35(2): 151-175. https://doi.org/10.1037/0003-066X.35.2.151 